\title{
Bioprinting Is Changing Regenerative Medicine Forever
}

\section{Scott Forrest Collins*}

ABSTRACT

3D printing, or solid freeform fabrication, applied to regenerative medicine brings technologies from several industries together to help solve unique challenges in both basic science and tissue engineering. By more finely organizing cells and supporting structures precisely in 3D space, we will gain critical knowledge of cell-cell communications and cell-environment interactions. As we increase the scale, we will move toward complex tissue and organ structures where several cell phenotypes will functionally and structurally interact, thus recapitulating the form and function of native tissues and organs.

\section{BACKGROUND}

In additive manufacturing (AM) or $3 \mathrm{D}$ printing (3DP), a polymer, metal, ceramic, or other structural component is printed in a single layer. The layer is moved away from the printhead by the thickness of that layer and the process is repeated. The stacked layers form the 3D object. There are numerous methods for printing $3 \mathrm{D}$ objects, including stereolithography [1-3], selective laser sintering [4,5], digital light processing [6], fused deposition modeling, metal processing, extrusion, and others [6]. In all methods, printed elements are often fixed together by thermal, chemical, mechanical, or optical methods [7]. The recent addition of low-cost thermal extrusion printers using low-cost plastic filaments has accelerated the field's growth and dramatically lowered the cost to entry to as little as a few hundred dollars. This has moved the technology

TeVido BioDevices, LLC, Austin, Texas.

*(Correspondence: scott@collinsbiomedical.com)

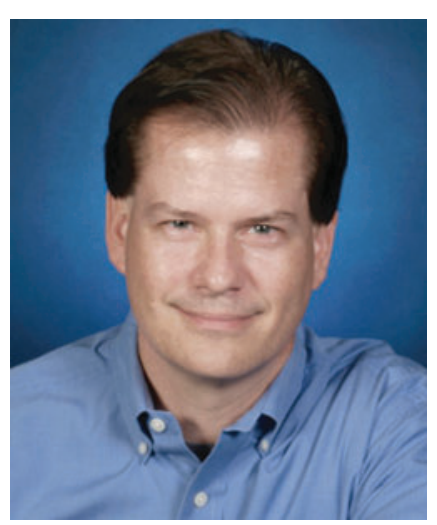

Scott Collins, PhD, is the chief technology officer and vice president of Research and Development at TeVido BioDevices

into the hands of individuals and has largely democratized AM.

The AM process starts with a computer rendering of the desired object to be formed. This can be accomplished by first scanning a 3D object or by designing it using a computer-aided design (CAD) or similar program. Next, the $3 \mathrm{D}$ rendering is sliced into individual layers of a given thickness. These images then become the map that the printer uses to print an individual layer. After one layer is printed, the stage is moved away from the printer head and then the next layer is formed over the first. For a more detailed description, please see one of the many primers on the subject.

Bioprinting (BP), a form of biofabrication, follows similar concepts [8]. One notable exception is that the structure being formed is often more complex, containing several differing components such as multiple cell phenotypes, scaffold gradients, and precisely placed signaling modalities. There is a time component to consider as well. Once a cell is placed in 3D space, it may move, remodel its environment, change phenotypic expression, or die due to inadequate nutrient availability and hydration. Unique considerations for BP are shown in Table 1. We are in the infancy of the BP industry. Techniques and technology will continue to evolve, moving us closer to on-demand printed body parts. 
Table 1. Unique Considerations for Common Cell-Based Bioprinting Applications

\begin{tabular}{|l|l|l|}
\hline & Bioprinting & Conventional 3D printing \\
\hline High temperature & Not allowed & OK \\
High/Low Pressure & Depends & OK \\
Hydration & Depends & OK \\
Sterility & Required & Doesn't matter \\
Cross-contamination & Required & Doesn't matter \\
High radiation (UV, etc.) & Depends on application & OK \\
\hline
\end{tabular}

The inks a bioprinter uses are up to the imagination of the user and are bound by the constraints of the printer. Emerging BP inks, or bioinks, include combinations of cells, cell aggregates, peptides, growth factors, hydrogels, scaffold components, and other materials [9]. Processing of the bioinks throughout the BP process requires care to assure that the cells and components in the ink are not killed or modified from the time inserted into the printer, throughout the printing process until printed onto a biocompatible substrate. There are several methods used to place bioink in precise 3D locations, including extrusion [10,11], thermal transfer, inkjet technology [12-15], laserinduced forward transfer (LIFT) [16], and other methods $[9,17]$.

The de novo construct formed by the BP process sets in motion a series of biologic processes based on the construct's design. As each layer is formed, the cells will begin to function and interact with their surroundings, thus making the $3 \mathrm{D}$-printed construct a complex multidimensional "living" construct that can remodel itself over time. If designed correctly, this interaction should provide research, clinical, and therapeutic benefit. On a clinical trajectory, we will likely progress from complex multicellular thin tissues used for in vitro diagnostics and tissue/organ support to vascularized simple tissues, increasing the potential thickness of engineered constructs and eventually culminating in the formation of functional whole-organ substitutes.
Several cell types can be used in the BP process. Limitations are generally related to the cell or cell aggregate size and morphology, as well as its ability to be transferred through the printing process in a healthy state. From the perspective of the cell and other fragile components of the bioink, considerations should be made as to temperature, shear forces, acceleration, and deceleration $[10,18,19]$. Simple tests can be performed that will provide insight into a cell's ability to survive a given printer's process in totality $[20,21]$.

Inkjet-based bioprinters typically offer high resolution and high speed but are limited to cell sizes smaller than the nozzle size, which can be $20 \mu \mathrm{m}$ in diameter or less. Extrusion-based bioprinters can print larger cells and cell aggregates at high cellular densities due to larger orifice size. However, they typically have lower resolution and require higher viscosity inks. LIFT-based bioprinters offer high resolution and high cell density but are often limited to a single ink type per print. The ultimate choice of bioprinter will ideally be based on the features of the tissue construct being formed.

Differentiated adult and adult progenitor cells should be considered and may be ideal when printing organs and tissues as they are closer to the final desired state. Using them would theoretically reduce the tissue incubation time prior to transplant. This in no way precludes the use of induced pluripotent stem cells, embryonic stem cells, extraembryonic cells, and adult stem cells in the BP process. In fact, it has been suggested that developmental mechanisms can be recapitulated in engineered tissues [22,23]. The combination of BP and stem cell technology offers the possibility of

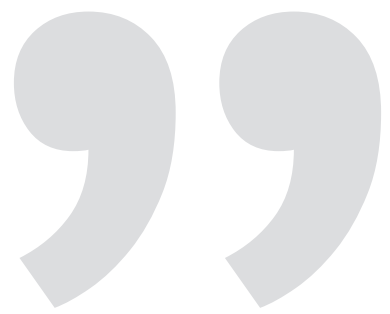

The combination of bioprinting and stem cell technology offers the possibility of printing small, developing organoids that will grow into fully functioning organs.

printing small, developing organoids that will grow into fully functioning organs while using the host as an incubator.

\section{Applications of bioprinters}

The BP process allows multiple bioinks to be deposited into precise locations, forming a 3D mosaic of cells, scaffolds, structures, and/or voids. The current resolution achievable for placement is typically on the order of $10 \mathrm{~s}$ to $100 \mathrm{~s}$ of $\mu \mathrm{m}$ in the $X-Y$ plane and 1s to $100 \mathrm{~s}$ of $\mu \mathrm{m}$ in the $Z$ plane [18]. This largely depends on the bioink as well as the printer being used ( $X-Y$ dimensions $)$ and the substrate/scaffold being printed on $(Z$ dimension). Unlike traditional 3DP, waterbased inks and papers may change in dimension as they are printed due to hydrophilicity of the substrate being printed onto and other factors.

Under a computer's control, a bioprinter can easily be set to form multiple replicates 
of a given experiment. It can also vary cell number and other bioink parameters in an effort to engineer optimal functioning constructs. This offers the possibility of rapidly assessing the effects of cellcell, cell-tissue, and cell-substrate interactions. By increasing the number of bioinks used, the complexity of the printed construct can be increased.

Theoretical structures formed can range from simple, such as a single cell deposited in a 3D scaffold, to more complex, such as an organized structure of multiple cell types forming a hierarchical vascular network surrounded by functional tissue components.

On a basic research level, a BP's automation will nicely allow the rapid screening of cellular interactions under controlled conditions. This will increase our understanding of how cells interact with their environment and allow researchers to better engineer future constructs. As cell-cell interaction is better understood [24], more complex formulations can be tested, moving us toward fully functional tissue constructs.

On a tissue engineering level, BPs will allow the formation of objects with higher resolution and complexity than conventional lab techniques allow. For instance, endothelial cells can be placed in an environment conducive to vascular formation within a more complex tissue structure such as skin, fat, or muscle. Without the incorporation of a functional vascular system, metabolically active tissue constructs are limited to thin structures that can be held close to a nutrient supply. It is this author's opinion that BP will dramatically accelerate our ability to produce thick soft tissue constructs by incorporating de novo vascular circuits.

\section{The future of BP}

BP will become more commonplace as research demonstrates new uses and methods. The quickest progress will likely come from basic stem cell research. BPs are ideally suited to creating experimental replicates with as few as one cell each, allowing the screening of cellenvironment and cell-cell interactions rapidly and at a relatively low cost per replicate [24].

The integration of vascular structure in tissue-engineered constructs has remained elusive, thus limiting metabolically active constructs to sub-millimeter thicknesses. Several methods are currently being investigated utilizing BP techniques to form vascular channels [25]. These methods include sacrificial channels that can later be seeded with endothelial cells, lines of endothelial cells that later coalesce into endothelial tubes, and free-standing tubular structures formed using several BP techniques. Also, Norotte et al. have used BPs that print cell aggregates in a scaffold-free substrate and have demonstrated that the cells will remodel and form a construct similar to an artery [11]. However, integrating vascular hierarchical structures spanning arteries down to capillaries has remained elusive. BPs can rapidly screen many possible solutions to this challenge, which is effectively limiting translatable tissue engineering constructs to sub-millimeter thicknesses.

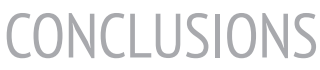

BP offers an automated method to form complex 3D cellular constructs for in vitro and in vivo use. The printing itself is accomplished by several common methods, including extrusion [10], thermal transfer, modified inkjet technology $[12,13,19]$, and others [26]. Bioprinters are controlled in ways similar to conventional $3 \mathrm{D}$ printers where a series of $2 \mathrm{D}$ renderings, or slices, are used to instruct the printer what to print on each layer. The underlying differences between BPs and 3D printers are the complex makeup of inks used and the sterile and environmental requirements for cell and tissue processing.

Though injected stem cells have been shown to provide therapeutic benefit in some cases, the transition from cellular therapy to engineered tissues and organs will likely require complex arrangements of cells and physical structures seen in native tissue. In the past, attempts have been made to seed targeted cellular therapy onto scaffold carriers in hopes that the cells would remodel into functional tissues [27]. BP offers an alternative where more complex structures can be formed with higher fidelity and in a reproducible manner.

Current efforts are to recapitulate the function of an organ as a whole for in vivo transplant akin to a donor organ transplant. We are not limited to this methodology. An intermediate approach may be to provide multiple microorgans that, used together, will recapitulate the function of the diseased tissue. By reducing the size of the constructs formed, we reduce some technical limitations such as large arterial networks. Another possibility is to form initial conditions necessary to influence progenitor cells to remodel into a functional, growing organ in situ. By creating a small seed-like structure in an appropriate environment, and implanting it early, we can use the patient as a bioreactor, allowing the small structure to develop into a mature organ. Many approaches exist. BP will allow us to iterate and replicate at a faster speed. Technological advances offered by BP will dramatically increase the rate we are able to iterate and report on new technological breakthroughs in regenerative medicine and other fields.

\section{Author Disclosure}

\section{Statement}

Dr. Collins holds the position of chief technology officer and has a financial interest in TeVido BioDevices, a company that plans to use BP for clinical applications.

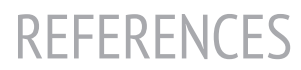

1. Melchels FP, J Feijen and DW Grijpma. (2010). A review on stereolithography and its applications in biomedical engineering. Biomaterials 31:6121-6130. 
2. Sun C and X Zhang. (2002). The influences of the material properties on ceramic micro-stereolithography. Sens Actuat A Phys 101:364-370.

3. Buyukhatipoglu K, R Chang, W Sun and AM Clyne. (2009). Bioprinted nanoparticles for tissue engineering applications. Tissue Eng Part C Methods 16:631-642.

4. Vail N, J Barlow, J Beaman, H Marcus and D Bourell. (1994). Development of a poly (methyl methacrylate-co-n-butyl methacrylate) copolymer binder system. J Appl Polym Sci 52:789-812.

5. Lam CXF, X Mo, S-H Teoh and D Hutmacher. (2002). Scaffold development using 3D printing with a starch-based polymer. Mater Sci Eng C 20:49-56.

6. Petrovic V, J Vicente Haro Gonzalez, O Jorda Ferrando, J Delgado Gordillo, J Ramon Blasco Puchades and L Portoles Grinan. (2011). Additive layered manufacturing: sectors of industrial application shown through case studies. Int J Prod Res 49:1061-1079.

7. Melchels FP, MA Domingos, TJ Klein, J Malda, PJ Bartolo and DW Hutmacher. (2012). Additive manufacturing of tissues and organs. Prog Polym Sci 37:1079-1104. 8. Wang X. (2012). Intelligent freeform manufacturing of complex organs. Artif Organs 36:951-961.

9. Fedorovich NE, J Alblas, JR de Wijn, WE Hennink, AJ Verbout and WJ Dhert. (2007). Hydrogels as extracellular matrices for skeletal tissue engineering: state-of-the-art and novel application in organ printing. Tissue Eng 13:19051925.

10. Chang R, J Nam and W Sun. (2008). Effects of dispensing pressure and nozzle diameter on cell survival from solid freeform fabrication-based direct cell writing. Tissue Eng Part A 14:41-48.
11. Norotte C, FS Marga, LE Niklason and G Forgacs. (2009). Scaffold-free vascular tissue engineering using bioprinting. Biomaterials 30:5910-5917.

12. Boland T, T Xu, B Damon and X Cui. (2006). Application of inkjet printing to tissue engineering. Biotechnol J 1:910 917.

13. Mironov V, T Boland, T Trusk, G Forgacs and RR Markwald. (2003). Organ printing: computer-aided jet-based 3D tissue engineering. Trends Biotechnol 21:157-161.

14. Nakamura M, A Kobayashi, F Takagi, A Watanabe, Y Hiruma, K Ohuchi, Y Iwasaki, M Horie, I Morita and S Takatani. (2005). Biocompatible inkjet printing technique for designed seeding of individual living cells. Tissue Eng 11:1658-1666.

15. Xu T, J Jin, C Gregory, JJ Hickman and T Boland. (2005). Inkjet printing of viable mammalian cells. Biomaterials 26:93-99.

16. Koch L, S Kuhn, H Sorg, M Gruene, S Schlie, R Gaebel, B Polchow, K Reimers, S Stoelting, N Ma, PM Vogt, G Steinhoff and B Chichkov. (2010). Laser printing of skin cells and human stem cells. Tissue Eng Part C Methods 16:847-854.

17. Nahmias Y, A Arneja, TT Tower, MJ Renn and DJ Odde. (2005). Cell patterning on biological gels via cell spraying through a mask. Tissue Eng 11:701-708.

18. Mironov V, N Reis and B Derby. (2006). Review: bioprinting: a beginning. Tissue Eng 12:631-634.

19. Saunders RE, JE Gough and B Derby. (2008). Delivery of human fibroblast cells by piezoelectric drop-on-demand inkjet printing. Biomaterials 29:193-203.

20. Nair K, M Gandhi, S Khalil, KC Yan, M Marcolongo, K Barbee and W Sun.
(2009). Characterization of cell viability during bioprinting processes. Biotechnol J 4:1168-1177.

21. Cui X, D Dean, ZM Ruggeri and T Boland. (2010). Cell damage evaluation of thermal inkjet printed Chinese hamster ovary cells. Biotechnol Bioeng 106:963969.

22. Rivron NC, J Rouwkema, R Truckenmüller, M Karperien, J De Boer and CA Van Blitterswijk. (2009). Tissue assembly and organization: developmental mechanisms in microfabricated tissues. Biomaterials 30:4851-4858.

23. Raof NA, NR Schiele, Y Xie, DB Chrisey and DT Corr. (2011). The maintenance of pluripotency following laser direct-write of mouse embryonic stem cells. Biomaterials 32:1802-1808. 24. Gruene M, M Pflaum, C Hess, S Diamantouros, S Schlie, A Deiwick, L Koch, M Wilhelmi, S Jockenhoevel and A Haverich. (2011). Laser printing of threedimensional multicellular arrays for studies of cell-cell and cell-environment interactions. Tissue Eng Part C Methods 17:973-982.

25. Hoch E, GE Tovar and K Borchers. (2014). Bioprinting of artificial blood vessels: current approaches towards a demanding goal. Eur J Cardiothorac Surg. [Epub ahead of print]; DOI: 10.1093/ejcts/ezu242.

26. Billiet T, M Vandenhaute, J Schelfhout, S Van Vlierberghe and P Dubruel. (2012). A review of trends and limitations in hydrogel-rapid prototyping for tissue engineering. Biomaterials 33:6020-6041. 27. Bajaj P, RM Schweller, A Khademhosseini, JL West and R Bashir. (2014). 3D biofabrication strategies for tissue engineering and regenerative medicine. Annu Rev Biomed Eng 16:247276. 